\title{
Erratum to: Application and Prospect of Mixed Reality Technology in Medical Field
}

Hong-zhi HU, Xiao-bo FENG, Zeng-wu SHAO, Mao XIE, Song XU, Xing-huo WU, Zhe-wei YE\#

Department of Orthopaedics, Union Hospital, Tongji Medical College, Huazhong University of Science and Technology, Wuhan 430022, China

(C) Huazhong University of Science and Technology 2021

\section{Current Medical Science}

https://link.springer.com/article/10.1007/s11596-019-1992-8

39(1):1-6,2019

The figure 6 in this article was previously published in a Letter to the Editor of the journal Surgical Innovation. The authors would like to apologize for the omission of a citation and add the reference 19 to this figure. 